This PDF is a selection from a published volume from the National Bureau of Economic Research

Volume Title: Social Security Programs and Retirement around the World: The Relationship to Youth Employment

Volume Author/Editor: Jonathan Gruber and David A. Wise, editors

Volume Publisher: University of Chicago Press

Volume ISBN: 978-0-226-30948-4; 0-226-30948-7

Volume URL: http://www.nber.org/books/grub08-1

Conference Date:

Publication Date: February 2010

Chapter Title: The Effects of Early Retirement on Youth Unemployment: The Case of Belgium

Chapter Author: Alain Jousten, Mathieu Lefèbvre, Sergio Perelman, Pierre Pestieau

Chapter URL: http://www.nber.org/chapters/c8251

Chapter pages in book: $(47$ - 76) 


\title{
The Effects of Early Retirement on Youth Unemployment The Case of Belgium
}

\author{
Alain Jousten, Mathieu Lefèbvre, Sergio Perelman, \\ and Pierre Pestieau
}

\subsection{Introduction}

Belgium is characterized by a very low labor force participation rate at older ages. According to Eurostat, in 2001, Belgium was in the leading group of European countries with respect to early retirement. On average, workers dropped out of the labor force at an average age of 57.9 years. Since then, the long-standing trend toward lower retirement ages tapered off. By 2005, the number increased to 59.6 years of age - and thus remains at a rather low level by international standards. Another indicator is the employment rate among the elderly workers, which is also far from satisfying the Lisbon criteria in terms of labor force activity rates of the elderly - and this in spite of the fact that more than half the time imparted by the EU has passed by without much action. ${ }^{1}$

Following the studies of Blondal and Scarpetta (1999) and Gruber and Wise $(1999,2003)$, there is a widespread recognition by academics and policymakers alike that the generosity of the social security and retirement

Alain Jousten is professor of economics at HEC-University of Liège and an IZA research fellow. Mathieu Lefèbvre is a post-doctoral researcher at HEC-University of Liège. Sergio Perelman is professor of economics at HEC-University of Liège. Pierre Pestieau is a professor emeritus of economics at HEC-University of Liège and a CORE faculty member.

The authors wish to thank for financial support under the "Communauté Française de Belgique" ARC contract (ARC 05/10-332) and FRFC (2.4501.05).

1. The Lisbon strategy was adopted for a ten-year period in 2000. It broadly aims to "make Europe, by 2010, the most competitive and the most dynamic knowledge economy in the world." One of the goals is to achieve a 50 percent employment rate of the elderly population (people age fifty-five to sixty-four). In Belgium, the elderly employment rate was 25 percent in 2000 and only 30 percent in 2005 , which is far from the objective at half period. 
systems has had a potentially decisive role in shaping the retirement patterns. Beyond the sheer generosity of the systems in terms of their benefit levels, it is by now recognized that marginal incentives toward exiting work play a decisive role in individual and collective decision making. By imposing explicit or implicit taxes on continued work, the systems favor early retirement and thus early exit from the labor force.

While reasons for such incentives toward early retirement can be multiple, one prominent justification often encountered is that giving older workers an incentive to leave the labor market frees up space for younger workers. ${ }^{2}$ This chapter addresses this issue from several perspectives within the Belgian context. Our aim is to derive a conclusive answer on the often cited potential for substitutability of employment of the old with that of the younger age groups.

The chapter is structured as follows. In section 1.2 we give some institutional background on the systems and regimes applicable to the older workers, as well as some specificity applicable to the young. Section 1.3 gives some theoretical arguments regarding both early retirement and youth unemployment. Section 1.4 proceeds on to a description of the data. Section 1.5 estimates the effect of incentive variables on activity rates, and documents the overall weak impact of parameters regarding the old on behavior of the young. Section 1.6 contains an alternative and more comprehensive specification for the existing difference between sex groups and section 1.7 concludes.

\subsection{Institutional Background}

The aim of this section is to describe the most important social protection schemes that provide for some form of replacement income when retiring from the labor market and when young and inactive. This chapter focuses on the wage earners. For the treatment of the young, this does not represent a significant limitation, as unemployment benefits are not accessible to the public sector anyway. For retirement, it thus exclusively models the wage earner pension and early retirement systems and does not consider the regimes applicable to either civil servants or the self-employed. The reason for this selective treatment lies in the severe data limitations, which do not allow us to identify which system a person belongs to (see section 1.4). Therefore, this chapter opts for a selective but detailed modeling strategy focusing on the single most important regime covering a wide majority of Belgian workers - while emphasizing the multitude of options available to these wage earners.

2. As an example, see the headline of a Belgian biweekly union newsletter: "More early retirement also means more jobs for young people!" (Syndicats, August 29, 2005). 


\subsubsection{The Policy Framework Regarding the Withdrawal from the Labor Force}

\section{Anticipated Retirement under the Private Sector Wage-Earner Scheme}

The public pension system is financed by tax-deductible employer and employee contributions and by contributions from the federal government's budget on a pay-as-you-go (PAYG) basis. Social security benefits are indexed to the cost of living and from time to time adjusted on a purely discretionary basis to the growth rate of the economy.

A pivotal year in the pension systems of the private sector wage earners is the year 1967. As a result of the merger of several existing pension schemes for different categories of workers the pension system takes on its current form. The basic attributes of the scheme are its PAYG financing mechanism, and the determination of a normal age of retirement set at sixty-five for men and at sixty for women. Anticipated retirement is allowed up to five years before the normal retirement age. Early retirement is accompanied by an actuarial reduction of 5 percent of the benefits by year of anticipation to compensate for the longer period of benefit claiming and the shorter period of contributions. The pension benefit is calculated on the basis of a fortyfive-year career for men and forty-year career for women. In this framework, retirement at the age of sixty-four, without reduction of the benefits, is allowed for men who have already forty-five years of career or who have been employed in severe work conditions. A special treatment is applicable to veterans, resistance fighters, and deported people who benefited from a national recognition. As of 1969 , they can anticipate the date of retirement by a maximum of five years without any reduction of benefits. Special regimes also remain in place for some specific sectors, such as most notably for coal mining and the maritime sector.

In 1977, a first step is taken to allow for early retirement within the aforementioned general pension system. The special early retirement schemes ("Régimes de prépension spéciale") give disabled workers or long-term unemployed at least sixty years of age for men and of fifty-five for women a bonus equal to the difference between the actual pension and the one they would receive if it was not reduced by the " 5 percent rule." This specific early retirement system is rather short-lived and is only applicable for a few years. It is formally terminated in 1979 for disabled workers and in 1982 for unemployed.

In 1983, a new scheme of early retirement is introduced within the framework of the pension system. The program of "Prépension de retraite" allows for male workers retiring with a maximum of five years of anticipation without reduction of the benefits if the employer commits to replacing the worker by an unemployed who is benefiting from a full-time compensation from the unemployment insurance. This second early retirement scheme 
will only end in 1991 with the introduction of the concept of a flexible retirement age in the pension system. Since 1987 (for women) and 1991 (for men), workers can freely choose the age of retirement without reduction of benefits as soon as age sixty, while maintaining separate normal retirement ages and full-career requirements for the two sexes. This means that the system has become significantly more flexible and generous as both the "prépension de retraite" and the " 5 percent rule" are no longer applicable. As a consequence, early retirement possibilities for women are significantly worsened, as before 1987 they could retire at a minimum age of fifty-five, which is now no longer possible.

The last reform affecting workers in our analysis dates back to 1997. Following up on a ruling by the European court of Justice requiring Belgium to put an end to the discrimination against men in the wage-earner pension system, the government decides to align the treatment of men and women by raising the female full career condition and the associated normal retirement age to the one applicable to men. Since 1997, the compulsory age of retirement for women has gradually been raised to sixty-one in 1997, sixty-two in 2000 , sixty-three in 2003, sixty-four in 2006, and will attain sixty-five in 2009, with the corresponding increase in the full-career requirement from forty to forty-five years. While aimed at eliminating discrimination, the measure has also a clearly beneficial impact in budgetary terms and contributes positively to the longer term viability of the regime.

Finally, the most recent reform to retirement incentives is introduced into the system in early 2007. As a result of the Intergenerational Solidarity Pact $^{3}$ negotiated between the social partners and the government in late 2005 , workers working beyond the age of sixty-two or beyond forty-four years of career can benefit from a pension supplement. The pension bonus of an amount of two euros per day worked beyond these limits augments the annual benefit payable, and this independently of the wage earned or the contributions accumulated. As such, it can be seen as a much stronger relative incentive for lower-wage earners than for higher-wage earners.

\section{Conventional Early Retirement}

Next to the wage-earner pension system, a parallel system of supplementary benefits for early retirement is created in 1973 for the old workers in case of firing: the conventional early retirement ("la Prépension conventionelle"). The announced goal of the scheme-which is not run by the pension administration - is to contribute toward a better distribution of

3. The Belgian Intergenerational Solidarity Pact includes some thirty measures aimed at reducing early retirement without changing the legal retirement age or current benefits already granted. Measures include limiting the number of people taking early retirement, stimulating employers to retain or hire older workers as well as making early retirement less attractive for both workers and employers. 
jobs between young and old. The program intends to achieve this goal by insuring a decent income to old workers that are forced to retire earlier than the normal pension age.

At the beginning, workers of age sixty and above who lose their job are eligible for the benefits of the system. One condition to be eligible for the regime is that the worker has been laid off by his employer, and a further condition stipulates that the employer has to recruit a person benefiting from full-time unemployment benefits as a replacement for the worker. The laid off elderly worker is then, in his turn, entitled to unemployment benefits with a top-up complementary benefit paid by the employer. This complementary benefit is equal to half the difference between the net wage and the unemployment benefit. A particularity of the system is that these early retirees are exempted from job search and - as for all unemployed - the time spent in the early retirement program is fully credited in the earnings file for pension purposes. As the crediting in the earnings history is done at a constant real value, it means that the worker's only financial loss is the immediate loss of purchasing power due to the lower level of the combined benefits with respect to the net wage previously earned.

If initially the age of early retirement is set at sixty, the limit is rapidly lowered by means of collective bargaining agreements within industries. As a result, there ultimately exists a variety of different regimes with different career requirements, minimum ages, replacement of the worker, and so forth, for different sectors and companies. In front of this imbroglio, the legislation is harmonized in 1986 by setting the minimum age at fifty-eight years. However, numerous exceptions persist with respect to the general rules. For example, while workers below the age of sixty do in theory have to be replaced when they are put onto early retirement, this is not the case for companies that are considered in economic difficulty or in restructuring, or if the company is closing or unable to find a suitable replacement. Similarly, while the age of fifty-eight is a priori the minimum access age, a lower age is possible in some sectors (steel, glass, textile, etc.) at the ages of fifty-five, fiftysix, or fifty-seven, depending on more stringent career conditions. Similar exceptions exist for some workers in the construction sector and some who work in shifts. Even more pronounced reductions in the minimum age are possible when the company is recognized as being in economic difficulty, under which case the age can be brought down to fifty-two years, or even fifty in special circumstances.

As a consequence of the Intergenerational Solidarity Pact of 2005, the conditions for access to the conventional early retirement scheme are becoming more stringent for all cases of early retirement before the age of sixty but not directly linked to companies in economic difficulties. As of January 2008 , the access to the conventional early retirement route at age fifty-eight is restricted to people with long working careers in a limitative list of "exhaust- 
ing" occupations. The access to routes opening up at ages fifty-five, fifty-six, and fifty-seven will also progressively be tightened and the reference ages increased over the next five years.

\section{Legal Early Retirement}

Between 1976 and 1982, another program of early retirement coexists with those exposed previously. The so-called system of legal early retirement ("Prépension légale") holds that the workers have access to the same status as the one provided by the conventional early retirement system, with the major difference being that the worker did not need to be laid off by his employer but could freely opt into the system. As a consequence of this different setting, the cost of the complementary benefit is not supported by the employer but by the social security budget with the restriction that the employer has to hire a young unemployed aged less than thirty and benefiting from full-time unemployment compensation. Access to this scheme is possible under an age condition of sixty for men and fifty-five for women.

\section{Part-Time Early Retirement and the System of Career Breaks}

In 1993 the possibility of work and half-time early retirement is introduced into the Belgian landscape. Access to the status is conditional on a written agreement between the worker and his employer. Further conditions relate to the age of the worker (no lower than fifty-five) as well as the replacement of the worker by a fully indemnified unemployed for the reduced portion of his schedule. This path is complex and is chosen by very few people-less than 1,000 people are registered in 2005.

Another route to early retirement is opened by the career break scheme, which is originally introduced in 1985 but later modified in 2001 to make it more flexible for early retirement. It allows workers to reduce their working hours or take a career break for any reason, while maintaining their social insurance protection and even usually getting a career break benefit. The scheme specifically attempts to allow workers age fifty and above to reduce their working hours and thus permit a progressive shift into retirement. It allows both a reduction to a four-fifth schedule and a reduction to a halftime schedule.

\section{Aged Unemployed Exempted from Job Search}

The last exit path out of the labor market is known as the regime for the "Old aged unemployed," a status that is introduced in 1985 into the Belgian social insurance landscape. According to this regime, an unemployed person aged at least fifty-five and who is out of his job for at least two years is exempted of job search and continues to receive the unemployment benefits without any restrictions in time or in availability for the job market. In 1996, the age of admission to the system is lowered to the age of fifty and the period of joblessness is lowered to one year. As a result, this scheme is 
widely used in the Belgian retirement landscape. In its most extreme version, employers use it to separate from older workers by compensating them with (large) lump sum compensations/side payments - this way avoiding the more complicated and stringent conventional early retirement route. The latter mechanism is also known in the Belgian context by the name of "Canada Dry" retirement arrangements, as it looks and tastes like early retirement but it formally is none. ${ }^{4}$

Faced with the growing importance of these arrangements, the government progressively introduces changes to the legislation to slow down the spread of its use and abuse. Since July 2004, new entrants to the system have to satisfy more stringent conditions to access the waiver with respect to the availability for job search. Under the new rules, only workers age fiftyeight and above or with very long careers can still benefit from the full job search waiver, while those below fifty-eight still have to be available for the labor market. However, while the younger jobless are increasingly subject to stricter controls of their availability for the job market, these same rules are not enforced on those age fifty and above-hence, making the changes less dramatic than they may seem at first sight.

Figures 1.1 and 1.2 present early exit routes over the period 1980 to 2005. They show for each year, at January 31, the percentage of men and women recorded as beneficiaries of each program. On both figures, we see how the structure changed over time with the introduction of new exit paths to retirement, namely the aged unemployed scheme in 1985 and its extension in 1996.

\subsubsection{Specific Unemployment Policies Targeted Toward the Young}

A specificity of the Belgian social insurance system is the generalized availability of unemployment benefits (called "waiting allowance") for young people on the pure basis of education. As of 1945 unemployment benefits are given on the basis of studies. Initially it is only implemented for people that have followed vocational schooling. Formally, there is no age limit but the individual has to claim benefits in the first year following the end of his studies. In 1951, the status is extended to people having completed apprenticeships. The waiting period before claiming the first benefit is set at seventy-five days. In 1968, the list of admissible graduates is extended to all secondary education levels (technical or general) and the age limit was generally set at twenty-five years of age. In 1980, the maximum age is pushed up to twenty-six, the waiting period increased from seventy-five days to 150 days, and in 1983 the one-year deadline on first claiming is eliminated. In 1985, the possibility of first claiming these benefits is introduced for people aged between twenty-six and thirty subject to a waiting period of 300 days. The

4. This alludes to an old European commercial for Canada Dry ginger ale that was said to have the color of beer without being it. 


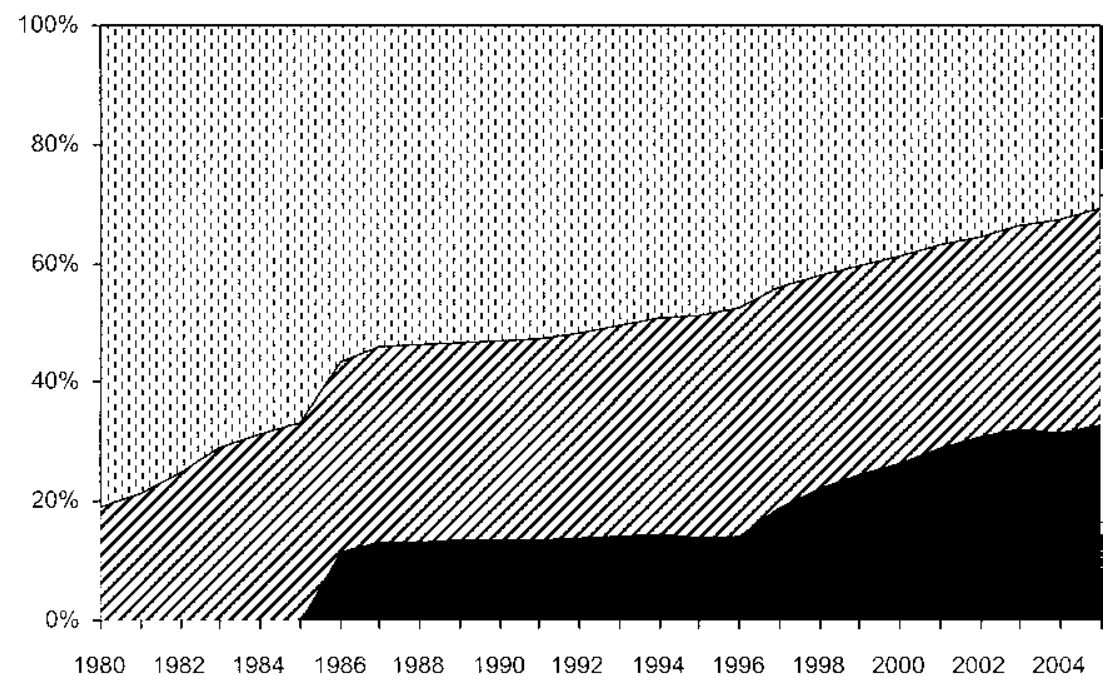

- Aged unemployed a Conventional early retirement $\square$ Anticipated retirement

Fig. 1.1 Exit paths to early retirement-Men

Source: Belgostat and National Office of Pension (ONP-RVP).

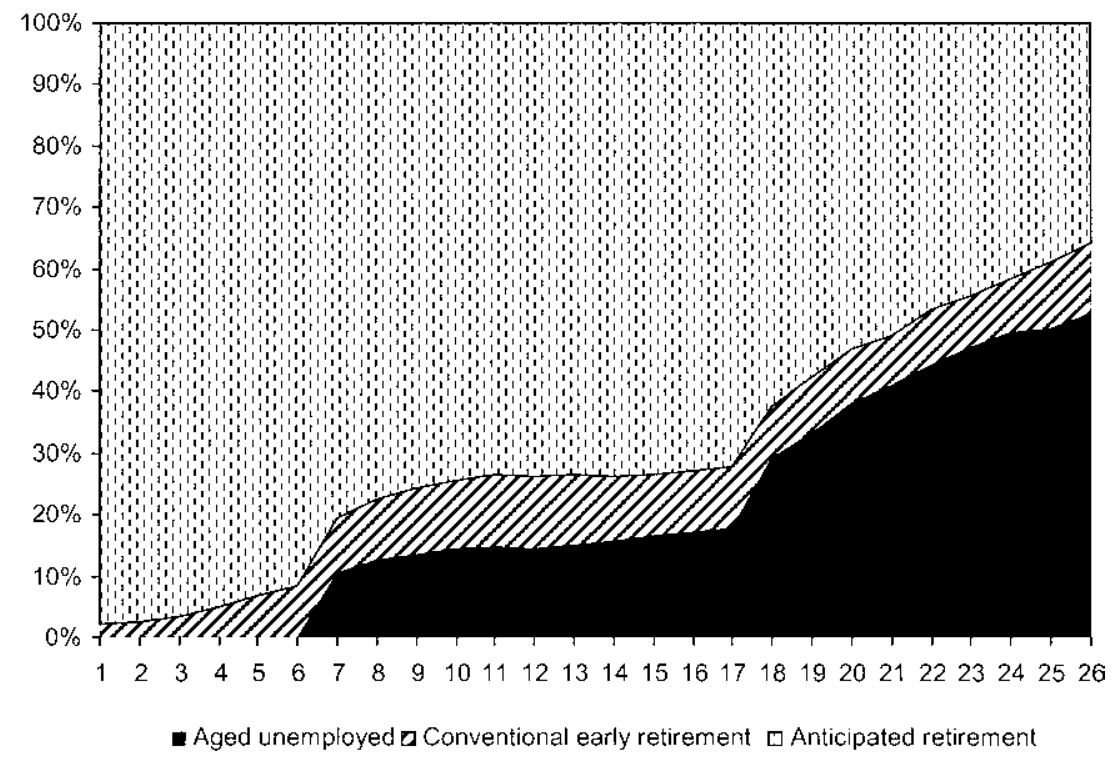

Fig. 1.2 Exit paths to early retirement-Women

Source: Belgostat and National Office of Pension (ONP-RVP). 
year 1994 is the last major reform of the system with waiting periods further increased for people belonging to different age brackets below the age of thirty. The new standards are 155 days for those aged less than eighteen, 233 days between eighteen and twenty-five, and 310 days between twenty-six and thirty, corresponding to six, nine, and twelve months, respectively.

Currently, almost every young person leaving school in Belgium is entitled to unemployment benefits without any work requirement. It is common for young people aged less than thirty to sign up with the regional Public Employment Service as a job seeker immediately upon receiving one's school diploma (usually high school or college/university). This enrollment entitles the graduate to an unemployment benefit awarded after the abovementioned age-dependent waiting period. This unemployment benefitwhich is awarded for an indefinite period of time - was at first based on the level of education attained by the graduate. Over time, it has progressively evolved into a lump sum amount, which is purely a factor of the family status of the person claiming the benefit. Administratively, the young unemployed receiving the "waiting allowance" is considered a job seeker and technically enters the category of persons benefiting from full-time unemployment benefits.

A number of jobs benefiting from tax and contributions exemptions are open to the young unemployed at the end of the waiting period. Consequently, when the waiting period increases one observes a similar increase in the rate of youth unemployment (ONEM 2001).

\subsection{Lump of Labor Fallacy and Youth Unemployment in Belgium}

The idea that forcing elderly workers out of the labor market before the statutory age of retirement would provide jobs for the unemployed young has been for a long time widely accepted in several European countries, particularly in Belgium, where youth unemployment is particularly high both in absolute and in relative terms. For most economists and (fortunately) an increasing number of Belgians, this view is based on the erroneous belief in a fixed amount of work, what is sometimes dubbed a "boxed economy." Economists call this allegedly widespread view the "lump of labor fallacy."

Those who make the fallacy claim fail to offer specific evidence of the supposed belief in a fixed amount of work. Yet it is too convenient to yield the burden of the proof on the advocates of the lump of labor fallacy. ${ }^{5}$ In this study we revisit the question of whether pre-retirement is a means to free up jobs for the young. Boldrin et al. (1999) have started to do so by comparing

5. This view is also called the lump-of-output fallacy since it assumes that output is unaffected by the job reallocation. While it seems that labor force exiting will affect the wage rate and inflation and then output (Layard, Nickell, and Jackman 1991). 


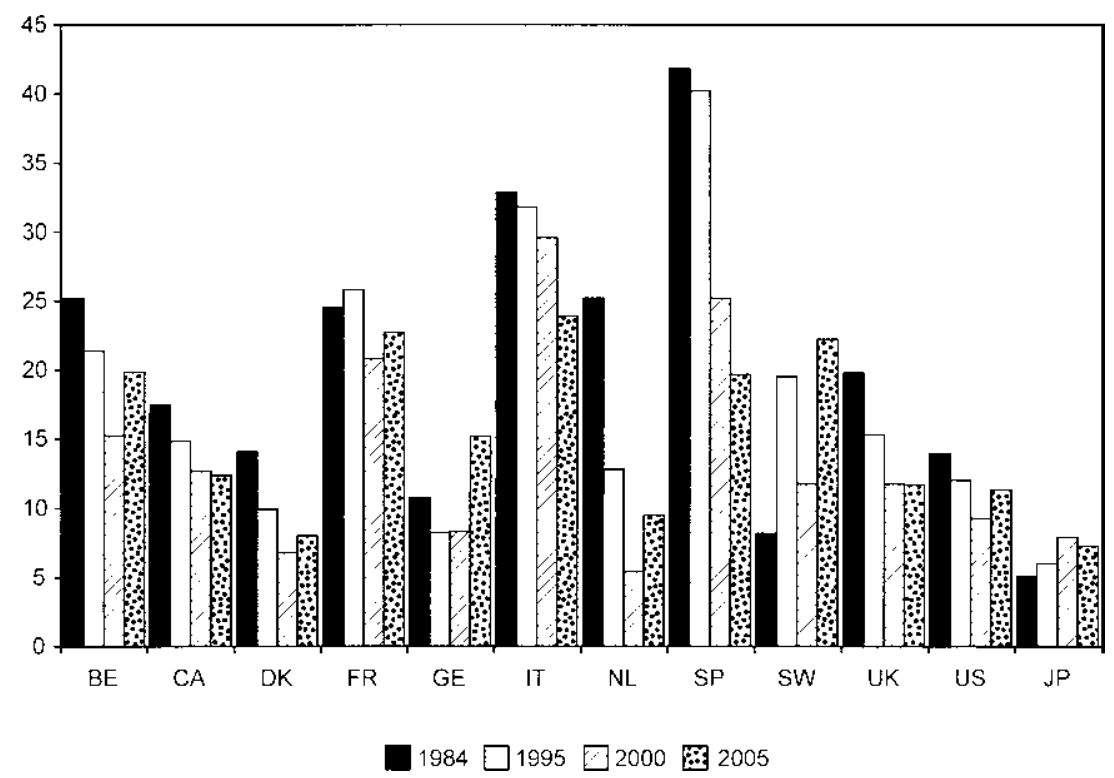

Fig. 1.3 Youth fifteen to twenty-four unemployment rates in OECD countries Source: OECD labor force database (2006a).

for several countries and several periods the relation between pre-retirement and youth unemployment. Their conclusion is negative but their methodology is questionable. They plot the exit rates from the labor force of older workers and the variation in the unemployment rate of young workers and do not find any negative link between the two variables.

What we want to do in this section is to look at the main characteristics of youth unemployment in Belgium over the last decades and to see whether such unemployment would decrease with an increase in the demand of labor. Implicitly, we assume that pre-retirement policies imply an increased demand for labor and that such a demand is relevant for the unemployed young. In other words, for the sake of the argument, we follow the reasoning of the advocates of the lump of labor.

Belgian youth unemployment is high and has tended to increase in recent years from 15 percent in 2000 to 20 percent in 2005 . The youth unemployment rate is about three times higher than the adult unemployment.

Figure 1.3 shows the differences across a number of Organization for Economic Cooperation and Development (OECD) countries over the years $1984,1995,2000$, and 2005 for the rate of unemployment of the young age fifteen to twenty-four. One sees that Belgium is in the same league as France, Italy, Spain, and Sweden - countries with very high youth unemployment.

A key feature of Belgian youth unemployment is that it concerns unskilled 
workers. Figure 1.4 gives the evolution of unemployment for three levels of education. One clearly sees that the rate of unemployment of unskilled has been increasing over the period 1992 to 2004 for both genders and is above the double of the rate of unemployment of young with medium or high levels of education.

Consider four standard explanations for youth unemployment in Belgium:

- Lack of professional training

- Mismatching

- Unemployment compensation combined with family arrangements

- Minimum wages and employment regulation

1. In Belgium, the transition from school to work is very abrupt. Fulltime education is the norm, with dual apprenticeship schemes remaining marginal. Internship is not an integral part of a student's school or university career.

2. Mismatching is another important cause of unemployment. Mismatching can be due to the educational system that is not sufficiently aimed at the needs of the industrial world but also to the lack of geographical mobility.

3. As we have seen, the young are entitled to unemployment compensations even without working experience. For unskilled young, these compensations are not high. However, combined with the possibility of staying within the family, these compensations generate a rather high reservation wage.

4. Belgium has a minimum wage, which is often viewed as a cause of unemployment, particularly among young workers. There is not much difference between the wages earned by young people and by adults. These relatively high wages paid to young workers can act as a barrier to the recruitment of unskilled young. Another barrier is the relatively strict set of employment regulation protecting insiders, coupled with the rules restricting the temporary contracts that many young workers have.

Assume that forcing elderly workers out of the labor force through all sorts of routes such as early retirement, disability, and unemployment generates employment opportunities for the young. This assumption assumes that the labor market is a zero-sum game, which clearly is rejected by most economists. Making this assumption, we want to show that even under this implausible case, it is not even sure that exiting elderly workers from the labor market does imply employment for the unemployed.

With mismatching, insufficient training, and high reservation wages as explanatory factors of unemployment, it is unlikely that increasing the quantity of jobs will generate more employment of the young. In other words, to 


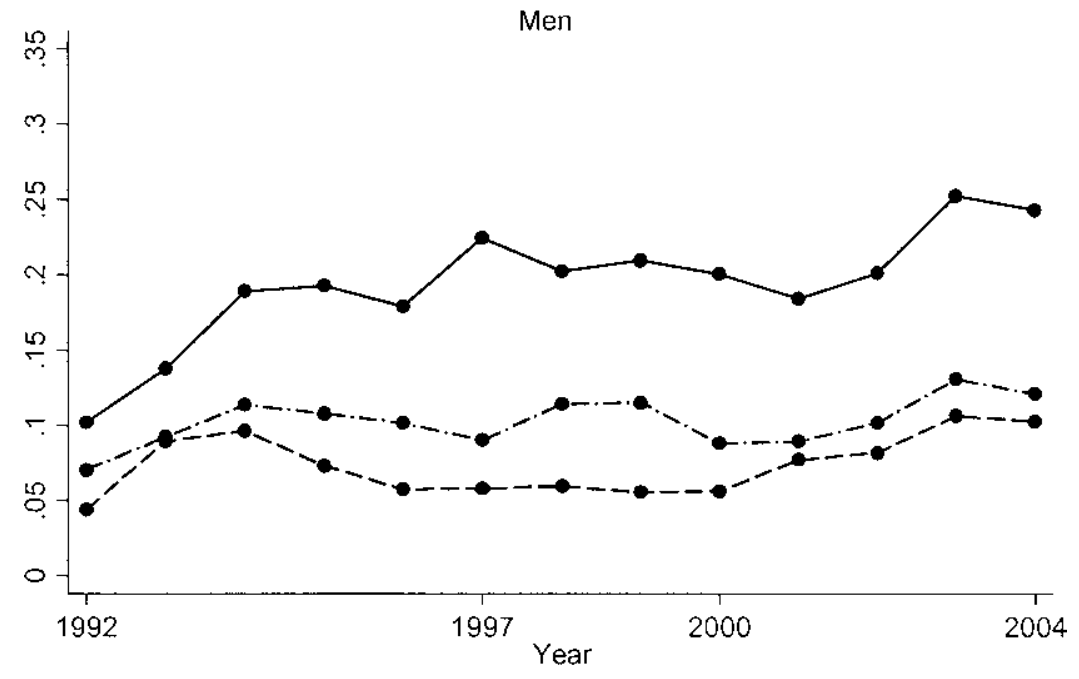

- - - - UR 20-29 High education -.-.- UR 20-29 Medium education UR 20-29 Low education

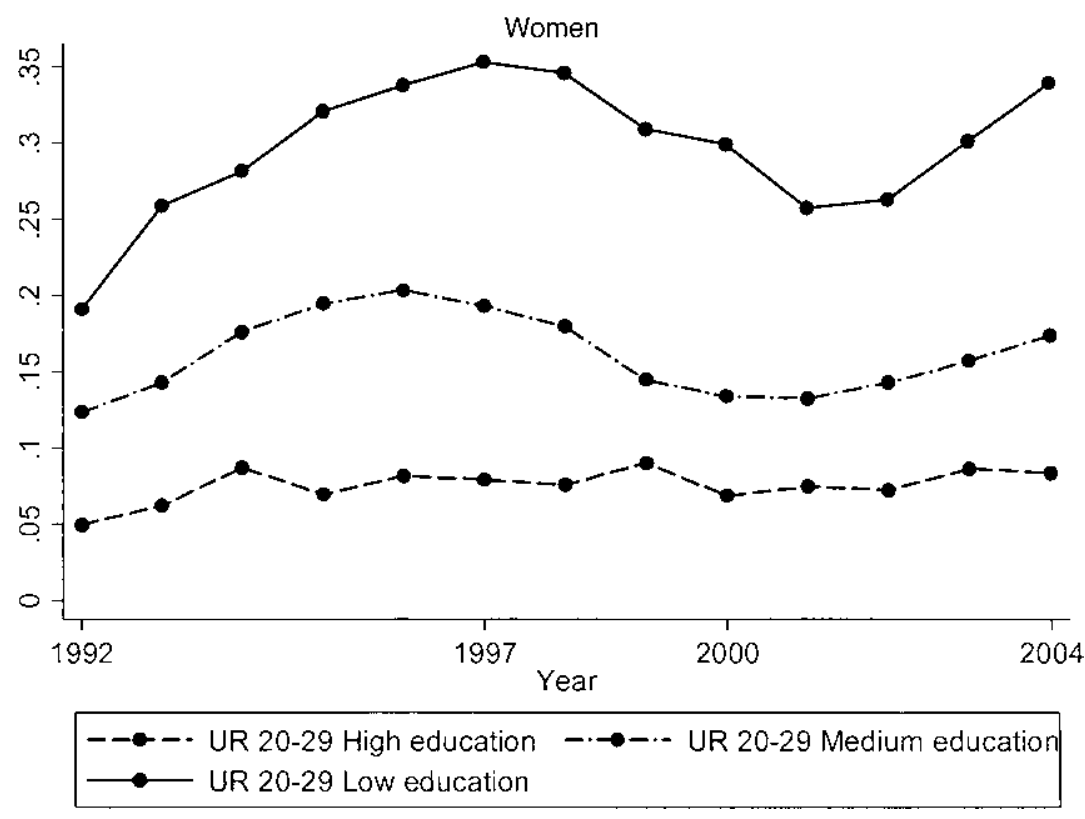

Fig. 1.4 Youth unemployment rates by education level and gender

Source: European Labor Force Surveys (1983-2004). 
foster youth employment, the solution is not early retirement but a better integration of the entering workforce as well as a reform of the educational system, of the unemployment insurance, and of the minimum wage. ${ }^{6}$ More importantly, a drastic change in values is crucial. But, as Kipling would say, "that is another story."

\subsection{The Data}

\subsubsection{Labor Force Data}

We subdivide the population into three subgroups: the older workers (fifty-five to sixty-four years of age), the prime aged workers (twenty-five to fifty-four) and the young (twenty to twenty-four). The precise cutoff points between these different groups are clearly of a key importance and mostly dictated by the institutional setting. Since in Belgium education is compulsory until the age of eighteen and data is generally available in five-year age brackets, we do not consider any five-year age bracket, including people subject to compulsory schooling. Therefore, the lowest age considered is the age of twenty.

Our analysis draws heavily on the European Labor Force Survey (LFS) for the time period 1983 to 2004. The data are used to derive labor force measures such as employment rate (ER), unemployment rate (UR), and labor force participation rate (LFP). Similarly, other demographic indicators are also computed for the individuals studied using the LFS data. For deriving the labor force indicators, we relied on the internationally recognized definitions as proposed by the International Labor Organization (ILO) rather than relying on administrative classifications. ${ }^{8}$

Other data are derived from OECD databases. In particular, the gross domestic product (GDP) indicators come from the OECD national accounts database (2006b),

Figures 1.5 and 1.6 present some illustrative data to set the stage. They illustrate the weak link between the unemployment (UR) of the two younger age groups in Belgium as compared to the labor force participation rate of the older workers (LFP). There does not seem to be a uniform relation between the labor force participation of the elderly and the employment possibilities of the young. While during the earlier period, reduced labor

6. High Employment Council (2007) showed that a large part of the unemployment in Brussels and Flanders are of foreign origin.

7. Furthermore, Belgium has a high rate of school attendance even between ages eighteen and twenty. In 1997, 90 percent of the young age eighteen to twenty were still at school.

8 . This means, for example, that people qualified as early retirees or aged unemployed according to the Belgian administrative classification would be classified as being out of the labor force under ILO standards. 


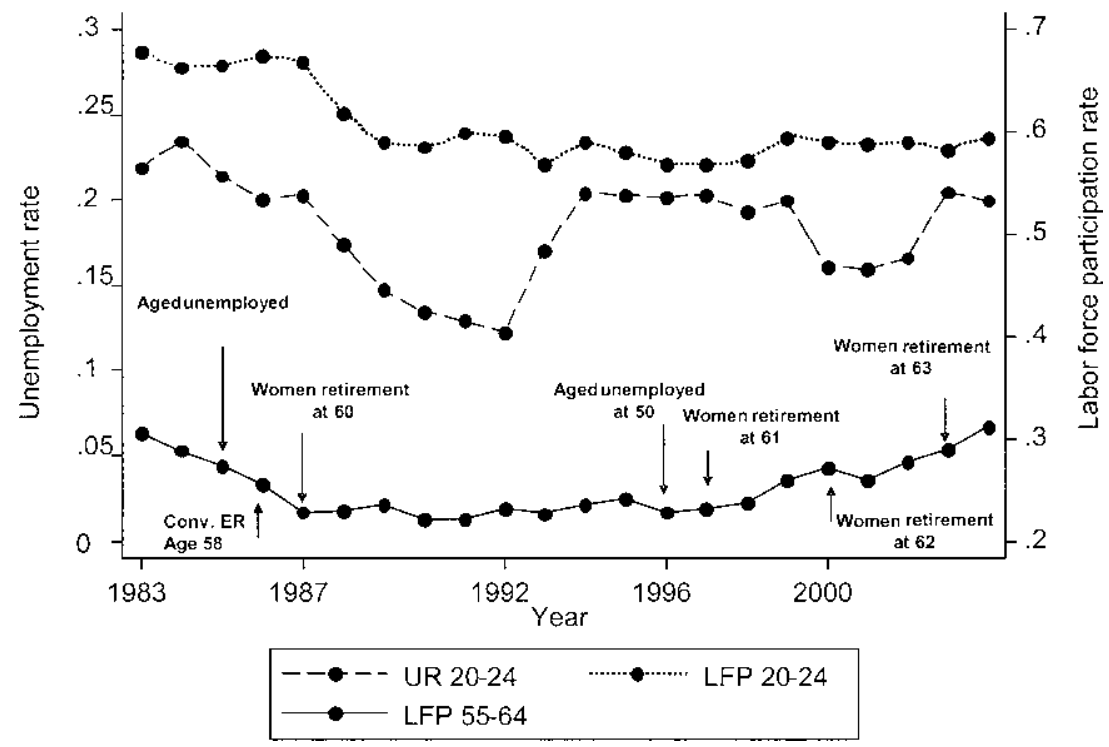

Fig. 1.5 Trends in unemployment and labor force participation of the young compared to the labor force participation of the old

Source: European Labor Force Surveys (1983-2004).

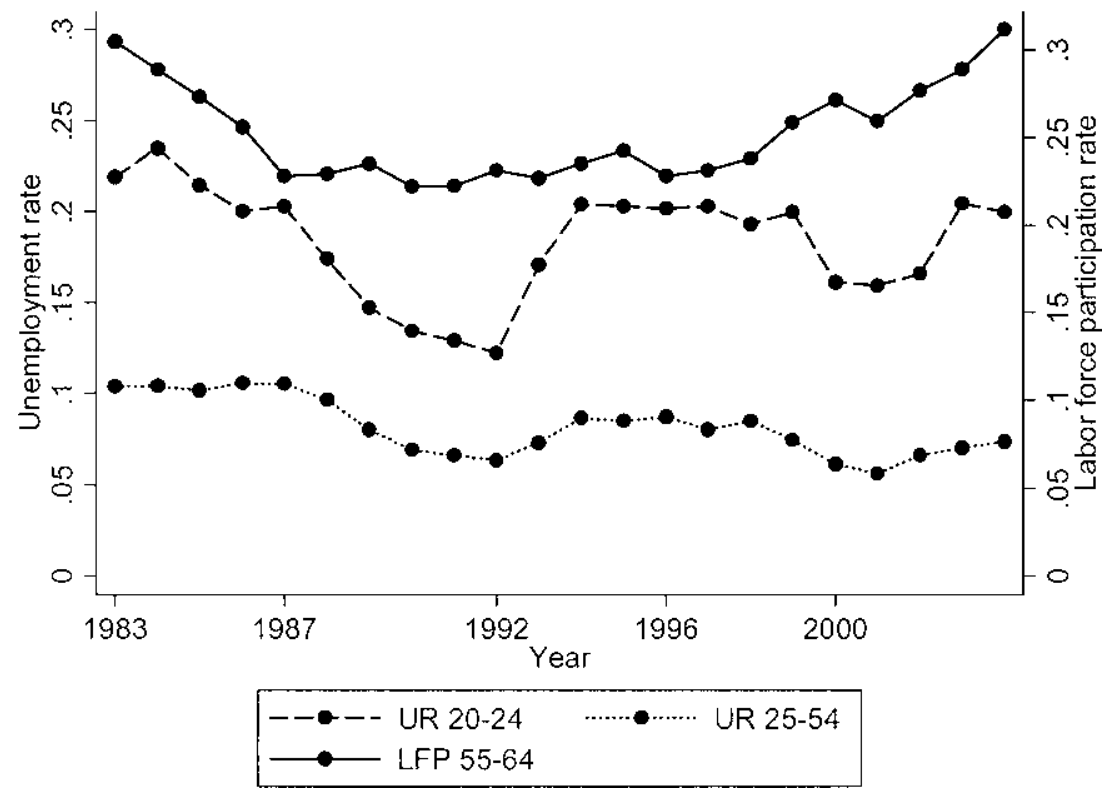

Fig. 1.6 Trends in unemployment of the young and prime aged workers compared to the labor force participation of the old

Source: European Labor Force Surveys (1983-2004). 


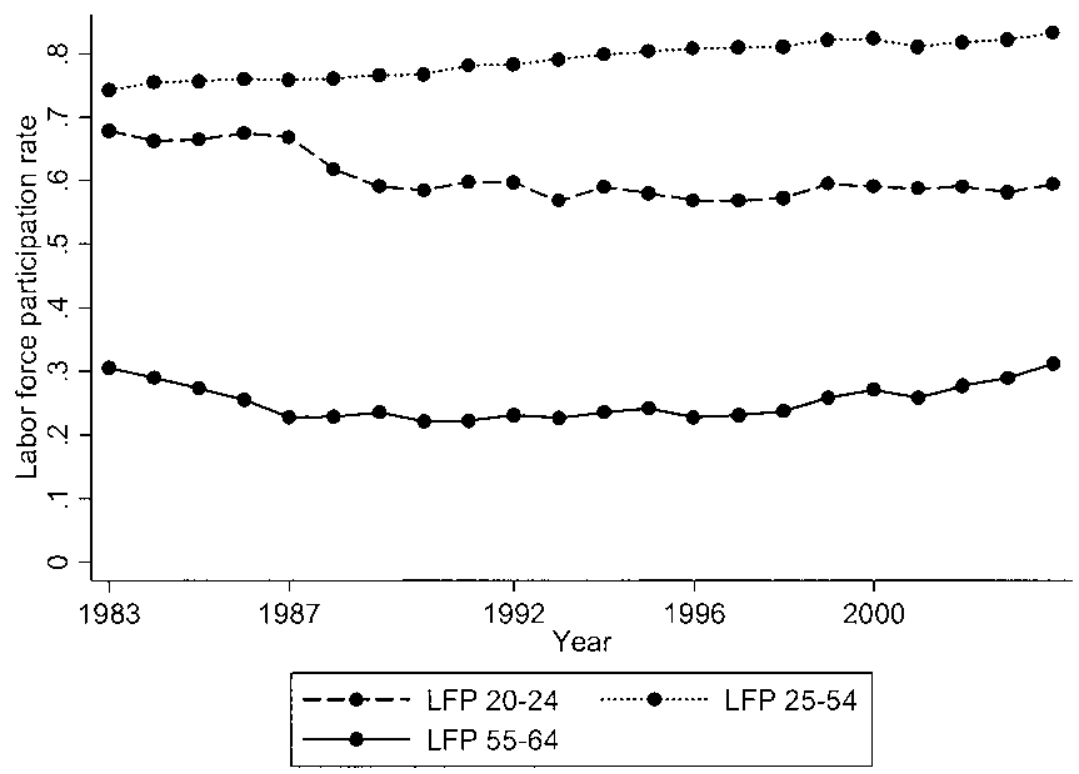

Fig. 1.7 Trends in labor force participation for the three age groups Source: European Labor Force Surveys (1983-2004).

force participation of the elderly seemed to move in parallel with lower unemployment for the young, this relation does not hold anymore since the middle of the 1990s. These results are hard to match with any specific policy change described in section 1.2. While the most important policy change was undoubtedly the reform of the 5 percent rule in 1991, no major effect seems to be observable in the labor market outcomes. On the contrary, this reform has been followed by a large increase in youth unemployment rate.

Finally, it is interesting to compare the labor force participation of the old to that of the young and the prime age as in figure 1.7. The graph reveals that the young are the only age group with a constantly falling labor force participation rate over the entire time period. Prime age workers have experienced a sustained growth in activity over the entire time period, whereas the same is also true for the older group since the middle of the 1990s.

\subsubsection{The Inducement to Retire}

Beyond these labor force data, we use another set of data on early retirement, namely indicators of incentive measures. The reason for constructing separate incentive measures instead of using the survey data is that we want to use a measure of the inducement to retire to explain labor force behavior. To avoid endogeneity problems in our ensuing empirical analysis, we need to develop a simulation approach by which we compute hypothetical benefit 
levels for a typical worker for all possible year and age cells covered by the labor force data that we described in the previous subsection.

To compute such aggregate incentive measures we perform benefit simulations akin to those presented by Jousten et al. (2005) for all cohorts under study. We then use the various benefit amounts derived for a hypothetical representative individual corresponding to the median of the income distribution. We compute these benefits profiles for the three main exit paths that this median individual may encounter: unemployment insurance, conventional early retirement, and normal retirement. Each of these paths yields different benefits. We then compute for each possible age and year as well as for each sex the present discounted value of these benefits using a 3 percent discount rate. We will continue to call the thus derived present discounted values Social Security Wealth $(W)$ in accordance with the previous literature on individual retirement incentives. ${ }^{9}$

Once these $W$ figures are obtained year by year for each individual exit path and possible retirement age, we aggregate those three incentives into one aggregate $W$ incentive measure that represents the global incentive to retire according to year and to age. Expressed in symbols, this is equivalent to deriving

$$
W=W_{\text {pen }}+p_{\text {unem }} \times \max \left[0, W_{\text {unem }}-W_{\text {pen }}\right]+p_{\text {ear }} \times \max \left[0, W_{\text {ear }}-W_{\text {pens }}\right],
$$

where $p_{\text {unem }}$ and $p_{\text {ear }}$ represents the cohort and year-specific probabilities of exiting by the specified routes of unemployment or early retirement. ${ }^{10}$ For pure reasons of simplicity, we assume that over the age span ranging from fifty to sixty-five the whole cohort leaves the labor market and goes into retirement - a rather reasonable assumption in the Belgian context given the quasi-compulsory nature of retirement at the latest when reaching the full retirement age. ${ }^{11}$ The exit probabilities are calculated using the LFS for the period of 1983 to 2004, and the results are rescaled to obtain a total departure by the age of sixty-five. Finally we average over sex to obtain one $W$ by cohort.

Figure 1.8 illustrates the trends in the incentive measure as experienced by successive cohorts of hypothetical Belgian median wage earners. It displays a secular upward trend in benefit levels for the successive cohorts, combined with a hump-shaped profile of benefit for each individual cohort. The only major benefit change over the period under study was the change in the

9. All these incentives are expressed in 2002 euros.

10 . We use the empirically observed age- and cohort-specific cumulative hazard until the normal retirement as a proxy for the probabilities of departure through the early retirement and unemployment pathways.

11. Technically, an individual can continue to work but largely loses his protection against layoffs. Furthermore, the continuation of work is only possible with the explicit written agreement on the part of the employer. 


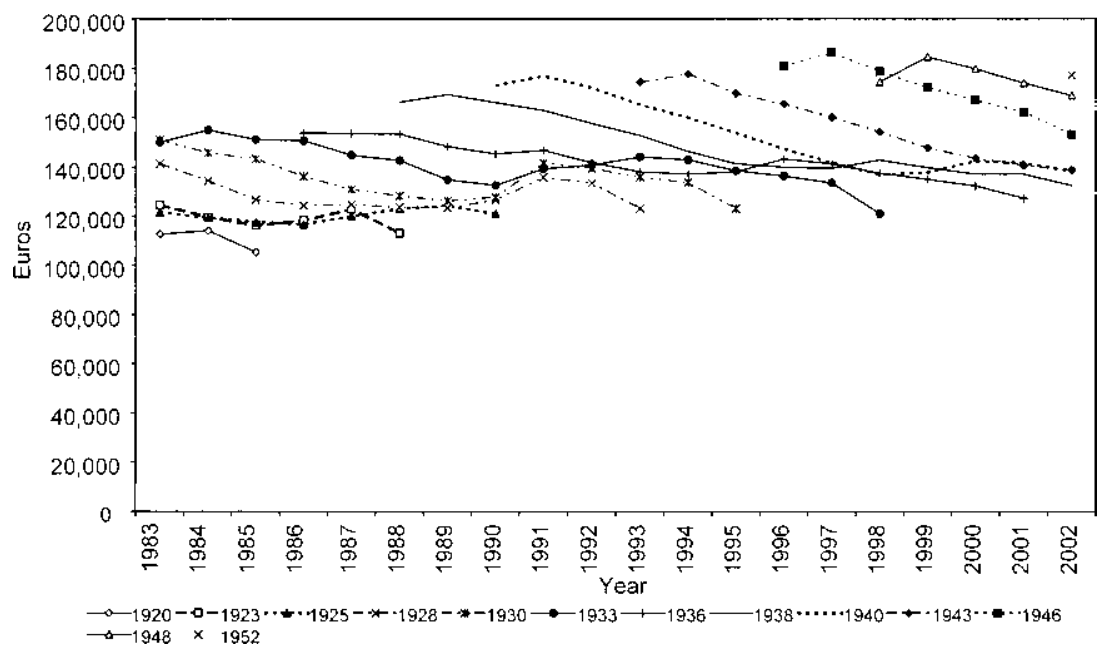

Fig. 1.8 SSW for selected cohorts by year

Source: Results from our own simulation.

actuarial adjustment rule in 1991. Unsurprisingly, it has the biggest impact on cohorts close to the early retirement age of sixty - which translates into an upward bump in the incentive variable for older cohorts in 1991. Other factors, such as the generalization of the exemption from job search in the middle of the 1990s, have a very limited effect, thus leading one to conjecture that even in the absence of a formal ruling unemployment beneficiaries were anyway already de facto exempted from job search. The impact of the expansion of the conventional early retirement provisions to the age of fiftyeight in 1986 was modest for retirement incentives, hence indicating that the prevalence of other routes must have been such that the importance of this legislative change was rather limited. Further aggregating up these yearand age-specific $W$, it is possible to compute a yearly index that takes into account the various incentives by age. We proceed to estimate two incentive indexes that are weighted sums of incentive indicators. The first one, denoted $\bar{W}$, is purely based on the age- and-year specific $W$ thus derived. The second indicator - that we will call the "inducement to retire," denoted $\bar{I}$ - is a mix of the concept of $W$ and that of Peak Value $(P V)$ :

$$
\begin{aligned}
\bar{W}(y)= & \sum_{a=50}^{a=65}\left[\frac{P(a, y)}{\sum_{a=50}^{a=65} P(a, y)}\right] \\
& \times\left[\frac{\sum_{t=0}^{a-50} W(a-t, y-t) \times \operatorname{LFP}(a-t, y-t-1)}{\sum_{t=0}^{a-50} \operatorname{LFP}(a-t, y-t-1)}\right]
\end{aligned}
$$




$$
\begin{aligned}
\bar{I}(y)= & \sum_{a=50}^{a=65}\left[\frac{P(a, y)}{\sum_{a=50}^{a=65} P(a, y)}\right] \\
& \times\left[\frac{\sum_{t=0}^{a-50} I(a-t, y-t) \times \operatorname{LFP}(a-t, y-t-1)}{\sum_{t=0}^{a-50} \operatorname{LFP}(a-t, y-t-1)}\right]
\end{aligned}
$$

with

$$
I(a, y)=W(a, y)+\alpha[W(a, y)-P V(a, y)] .
$$

In the above expressions, $W$ represents the Social Security Wealth, and $P V$, the Peak Value. The $P V$ at age $a$ is defined as the maximum $W$ the individual can obtain by optimally choosing the time of retirement between the current moment $y$ and the statutory retirement age. Variable LFP is the labor force participation and $P$ is the proportion of retired persons of that age in that year, and both variables are derived using the LFS.

In equation (1) the concept $I$ summarizes two broad pieces of information. The first element on the right-hand side expresses the idea that the larger $W$, the larger the wealth a person has at his avail, and thus the easier it is for him to retire early. The second term expresses the idea that by waiting till the optimal time - as summarized by the gain in present discounted value between immediate retirement and the optimal retirement maximizing the present discounted value - the individual faces an incentive to stay at work. Finally, $\alpha$ is a coefficient that reflects the notion of discounting future revenue gains with respect to present wealth-beyond the pure effect of financial discounting as captured by the 3 percent discount rate. ${ }^{12}$ The idea behind this parameterization is to capture the individual's possible impatience, making them less willing or incapable $(\alpha=0)$ to consider future revenue or wealth gains before they become available.

We endogenously estimate the parameter value for $\alpha$ using two different procedures. The results of these estimations are displayed in table 1.1. The equation we estimate is given by

$$
\mathrm{LFP}_{\text {old } t}=\gamma \bar{W}_{t}+\varphi\left(\overline{W_{t}-P V_{t}}\right)+\phi X_{t}+\varepsilon_{t} .
$$

The first two terms on the right-hand side of equation (2) correspond to the components of the incentive indicator $I$, and $X$ is a vector of control variables. The implied value of $\alpha$ thus corresponds to the ratio of $\varphi$ over $\gamma$.

Then, we validate the previous results using an iteration process on $\varphi$ and $\gamma$ that attempts to maximize $R^{2}$ as an objective function-a process one could qualify as a simplified maximum likelihood approach.

In table 1.1, the value of $\alpha$ given by both iteration and regression pro-

12. Setting the financial discount rate to infinity is equivalent to assuming the individual is perfectly liquidity constrained. 
Estimating the parameters of I

\begin{tabular}{llcccc}
\hline & $\gamma$ & $\varphi$ & $\alpha$ & $R^{2}$ & Implied $\bar{I}$ weighting \\
\hline $\begin{array}{l}\text { 1. Iterating over } \gamma \text { and } \varphi \\
\text { with } 0.25 \text { intervals } \\
\text { and regressing LFP } \\
\text { of old on } \bar{I} \text { and } \\
\text { covariates }\end{array}$ & 0.5 & -1.25 & -2.5 & 0.924 & $0.5 \times \bar{W}-1.25 \times \overline{W-P V}$ \\
$\begin{array}{l}\text { 2. Iterating over } \varphi \text { with } \\
\gamma=1 \text { with } 0.25\end{array}$ & 1 & -2.25 & -2.25 & 0.924 & $1 \times \bar{W}-2.25 \times \overline{W-P V}$ \\
$\begin{array}{l}\text { intervals and } \\
\text { regressing LFP of old } \\
\text { on } \bar{I} \text { and covariates }\end{array}$ & & & & & \\
3. Time series regression \\
of $L F$ of old on $\bar{W}$ \\
and $\overline{W-P V}$
\end{tabular}

Notes: Reported is the coefficient on the inducement to retire in thousands. Covariates include GDP per capita, the growth in GDP per capita, and the share of GDP coming from manufacturing sector, $\alpha$ corresponds to the ratio of $\varphi$ over $\gamma$.

***Significant at the 1 percent level.

**Significant at the 5 percent level.

*Significant at the 10 percent level.

cedures is negative, which is inconsistent with the methodology proposed. The reason for such a result can be found in the methodology itself. The computation of this indicator of the inducement to retire likely results in an overly aggregated and averaged indicator, especially in the context of the multitude of early retirement pathways as present in Belgium. In the next section, we will only use $\bar{W}$ as an incentive since the negative value of $\alpha$ leads us to assume that it is nil in the econometric estimations. If $\alpha=0, \bar{I}$ is equal to $\bar{W}$. We will come back to the estimation of $\bar{I}$ in section 1.6 where we study women and men separately.

\subsection{Regression Analysis}

Moving beyond the purely descriptive analysis of the previous section, we now turn to ordinary least squares (OLS) regression analysis. It proceeds in two steps. The first step is an econometric study of the direct relationship between the employment of the old and the employment of the young. The second step is an analysis of how the incentives faced by the old directly influence the employment outcomes of the young.

For the first type of analysis, we estimate both regressions in levels and in differences. We settle on four specifications: in levels, with a three-year lag and also with five-year difference and five-year log difference. The levels regression links the labor force performance measures of the young and middle-aged to those of the old: 


$$
\begin{aligned}
& A_{t}=\theta+\beta B_{t}+\delta X_{t}+\varepsilon_{t} \\
& A_{t}=\theta+\beta B_{t-3}+\delta X_{t}+\varepsilon_{t}
\end{aligned}
$$

where $A_{t}$ is the UR or the ER for either youth or prime age population. Similarly, by extension, we consider a regression of the percent of young still in an educational program ( $\mathrm{SCH}$ ). Variable $B_{t}$ is either the labor force participation rate of the old workers, and $X_{t}$ is a set of covariates that includes GDP per capita, the growth in GDP per capita, and the share of GDP coming from manufacturing sector.

The difference specification takes the following form:

$$
\begin{aligned}
A_{t+5}-A_{t} & =\theta+\beta\left[B_{t+5}-B_{t}\right]+\delta\left[X_{t+5}-X_{t}\right]+\varepsilon_{t+5}-\varepsilon_{t} \\
\ln A_{t+5}-\ln A_{t} & =\theta+\beta\left[\ln B_{t+5}-\ln B_{t}\right]+\delta\left[\ln X_{t+5}-\ln X_{t}\right]+\varepsilon_{t+5}-\varepsilon_{t} .
\end{aligned}
$$

Results are reported in table 1.2. We run the regressions with and without control variables. As exposed previously, table 1.2 presents four alternative specifications in order to identify clearly the likely effects of elderly labor force participation on younger labor outcomes. The table also shows the estimated effect of the activity of elderly on the proportion of youth in school. One immediate observation is that elderly participation seems to play a more important role when controlling for other effects. Thus, we will pay more attention to these results.

Whatever one of the first three specifications, when they are significant, the coefficients are of the same sign and magnitude. Concerning the youth regressions, the results are contradictory. The labor force participation of the old appears to have a positive impact on youth unemployment rate and also a positive impact on the youth employment rate..$^{13}$ On the contrary, it has, when significant, a negative effect on the rate of schooling. As explained before, the rate of employment is much more relevant to account for activity in youth than one minus the rate of unemployment. We may thus conclude that the elderly participation has a positive effect on youth employment and schooling.

The five-year log difference specification contrasts with these results. The effect on youth unemployment disappears but we still have the same kind of effects on the employment and schooling. The regressions between older and prime age workers seem to display a slight substitution between those workers. Yet for the five-year log difference specification, we do not find any effect on youth employment but a negative effect on unemployment.

We now turn to the second exercise that tries to relate the incentives faced

13. It might be useful to remember that unemployment rate is not one minus employment rate. If we denote $P$ total population, $L$ active population, and $U$ unemployed population, the unemployment rate is $U / L$ and the employment rate is $(L-U) / P$. 
Table 1.2

Direct effect of elderly labor outcomes on the young (women and men combined)

\begin{tabular}{|c|c|c|c|c|c|}
\hline \multirow[b]{2}{*}{ Specification } & \multicolumn{3}{|c|}{ Youth 20 to 24} & \multicolumn{2}{|c|}{ Prime age 25 to 54} \\
\hline & UR & ER & $\mathrm{SCH}$ & UR & ER \\
\hline \multicolumn{6}{|c|}{ No controls } \\
\hline Levels & $\begin{array}{l}0.539^{* *} \\
(0.217)\end{array}$ & $\begin{array}{l}0.067 \\
(0.219)\end{array}$ & $\begin{array}{c}0.081 \\
(0.278)\end{array}$ & $\begin{array}{l}0.056 \\
(0.124)\end{array}$ & $\begin{array}{c}0.094 \\
(0.262)\end{array}$ \\
\hline 3-year lag & $\begin{array}{l}0.328 \\
(0.278)\end{array}$ & $\begin{array}{l}0.589 * * \\
(0.235)\end{array}$ & $\begin{array}{c}-0.627^{*} \\
(0.297)\end{array}$ & $\begin{array}{l}0.337^{* *} \\
(0.116)\end{array}$ & $\begin{array}{c}-0.589^{* *} \\
(0.248)\end{array}$ \\
\hline 5-year difference & $\begin{array}{l}0.591 \\
(0.357)\end{array}$ & $\begin{array}{l}0.292 \\
(0.208)\end{array}$ & $\begin{array}{c}-0.092 \\
(0.171)\end{array}$ & $\begin{array}{l}0.116 \\
(0.136)\end{array}$ & $\begin{array}{c}-0.089 \\
(0.089)\end{array}$ \\
\hline $\begin{array}{l}\text { 5-year log } \\
\text { difference }\end{array}$ & $\begin{array}{l}0.883 \\
(0.549)\end{array}$ & $\begin{array}{l}0.152 \\
(0.111)\end{array}$ & $\begin{array}{c}-0.075 \\
(0.132)\end{array}$ & $\begin{array}{l}0.296 \\
(0.448)\end{array}$ & $\begin{array}{c}-0.039 \\
(0.032)\end{array}$ \\
\hline \multicolumn{6}{|c|}{ With controls } \\
\hline Levels & $\begin{array}{l}0.619^{* * * *} \\
(0.180)\end{array}$ & $\begin{array}{l}0.185 \\
(0.157)\end{array}$ & $\begin{array}{c}-0.118 \\
(0.129)\end{array}$ & $\begin{array}{l}0.151^{* *} \\
(0.068)\end{array}$ & $\begin{array}{c}-0.116^{* *} \\
(0.054)\end{array}$ \\
\hline 3-year lag & $\begin{array}{l}0.534^{* *} \\
(0.221)\end{array}$ & $\begin{array}{c}0.372 * \\
(0.211)\end{array}$ & $\begin{array}{c}-0.259 \\
(0.173)\end{array}$ & $\begin{array}{l}0.273^{* * *} \\
(0.076)\end{array}$ & $\begin{array}{l}-0.262 * * * \\
(0.048)\end{array}$ \\
\hline 5-year difference & $\begin{array}{l}0.683^{* * * *} \\
(0.139)\end{array}$ & $\begin{array}{l}0.351^{* *} \\
(0.125)\end{array}$ & $\begin{array}{c}-0.099 \\
(0.153)\end{array}$ & $\begin{array}{l}0.198 * * * \\
(0.038)\end{array}$ & $\begin{array}{l}-0.166^{* *} \\
(0.056)\end{array}$ \\
\hline $\begin{array}{l}\text { 5-year log } \\
\text { difference }\end{array}$ & $\begin{array}{l}0.093 \\
(0.294)\end{array}$ & $\begin{array}{l}0.408^{* * * *} \\
(0.108)\end{array}$ & $\begin{array}{l}-0.330^{*} \\
(0.169)\end{array}$ & $\begin{array}{l}0.092 \\
(0.294)\end{array}$ & $\begin{array}{l}0.408 * * * \\
(0.107)\end{array}$ \\
\hline
\end{tabular}

Notes: Reported is the coefficient on elderly participation rate. Covariates include GDP per capita, the growth in GDP per capita, and the share of GDP coming from manufacturing sector.

*** Significant at the 1 percent level.

$* *$ Significant at the 5 percent level.

*Significant at the 10 percent level.

by the elderly to the labor market outcomes of the younger cohorts. As discussed in section 1.4, this approach has the advantage of being less prone to endogeneity problems than the approach just presented.

Table 1.3 presents only the results for $\bar{W}$ (and not for $\bar{I}$ ) since the estimations of section 1.4 lead us to consider a value of $\alpha$ equal to zero. The variable $\bar{W}$ explains very well the fall in labor force participation of older persons, which is a prerequisite for using it as an instrumental variable in the following estimations. The regression coefficients when considering younger cohorts outcomes are hardly significant in levels but we observe higher significance with the five-years' difference specification. The estimates confirm results obtained with labor outcomes regressions. It is difficult to observe any clear result concerning the younger people, especially if we have some doubt about youth unemployment rate as a suitable indicator. The effect, if any, on the prime age workers indicates some substitution between elderly and prime age workers. 
Table 1.3

Direct effect of the inducement to retire (women and men combined)

\begin{tabular}{|c|c|c|c|c|c|c|}
\hline \multirow[b]{2}{*}{$\begin{array}{l}\text { Using } \bar{W} \text { as an } \\
\text { explanatory variable }\end{array}$} & \multicolumn{3}{|c|}{ In level } & \multicolumn{3}{|c|}{ In 5-years difference } \\
\hline & Coefficient & $\begin{array}{l}\text { Standard } \\
\text { error }\end{array}$ & $R^{2}$ & Coefficient & $\begin{array}{l}\text { Standard } \\
\text { error }\end{array}$ & $R^{2}$ \\
\hline LFP of old & $-0.820 * * *$ & 0.101 & 0.823 & $-0.806^{* * *}$ & 0.132 & 0.819 \\
\hline $\begin{array}{l}\text { Unemployment of } \\
\text { young }\end{array}$ & $-0.487 * *$ & 0.226 & 0.493 & $-0.799 * * *$ & 0.078 & 0.978 \\
\hline $\begin{array}{l}\text { Employment of } \\
\text { young }\end{array}$ & -0.148 & 0.183 & 0.547 & -0.125 & 0.169 & 0.688 \\
\hline School of young & -0.069 & 0.135 & 0.849 & $-0.237 *$ & 0.108 & 0.735 \\
\hline $\begin{array}{l}\text { Unemployment of } \\
\text { prime age }\end{array}$ & -0.059 & 0.084 & 0.720 & $-0.179 * * *$ & 0.051 & 0.929 \\
\hline $\begin{array}{l}\text { Employment of } \\
\text { prime age }\end{array}$ & 0.040 & 0.061 & 0.963 & 0.081 & 0.066 & 0.698 \\
\hline
\end{tabular}

Notes: Reported is the coefficient on the inducement to retire in thousands. Covariates include GDP per capita, the growth in GDP per capita, and the share of GDP coming from manufacturing sector.

***Significant at the 1 percent level.

**Significant at the 5 percent level.

* Significant at the 10 percent level.

\subsection{Alternative Specification: Women and Men Separated}

Until now we have considered the aggregate labor market performance. Realities change when we differentiate according to sex. Indeed, the labor outcomes of men and women have been largely different in the past decades. The growing participation of women, for example, has clearly changed the situation of the labor market. Figures 1.9, 1.10, and 1.11 present these different patterns. On figure 1.9, we observe that if both activity of young men and women has slightly decreased during the period, the unemployment rates of the two groups have evolved in a different direction. The young men unemployment rate has increased while the young women unemployment rate has decreased. On figure 1.10, the unemployment rate of prime-age men and women is displayed. Here we also see that the women unemployment rate has decreased during the period considered, which is not the case for men. Finally, figure 1.11 presents the labor force participation of the three age groups. Both older and prime age women's activity has been increasing.

While the earlier regressions only took into account the average behavior of labor outcomes in Belgium, we propose to run the same regressions when differentiating by sex the left-hand side. In other words, we still consider the effect of labor force participation of all elderly workers but we account for differences between young men and women. The previous figures show that in Belgium, the labor market performances of men and women are different. The idea is to explore whether the diverging labor outcomes of younger age 

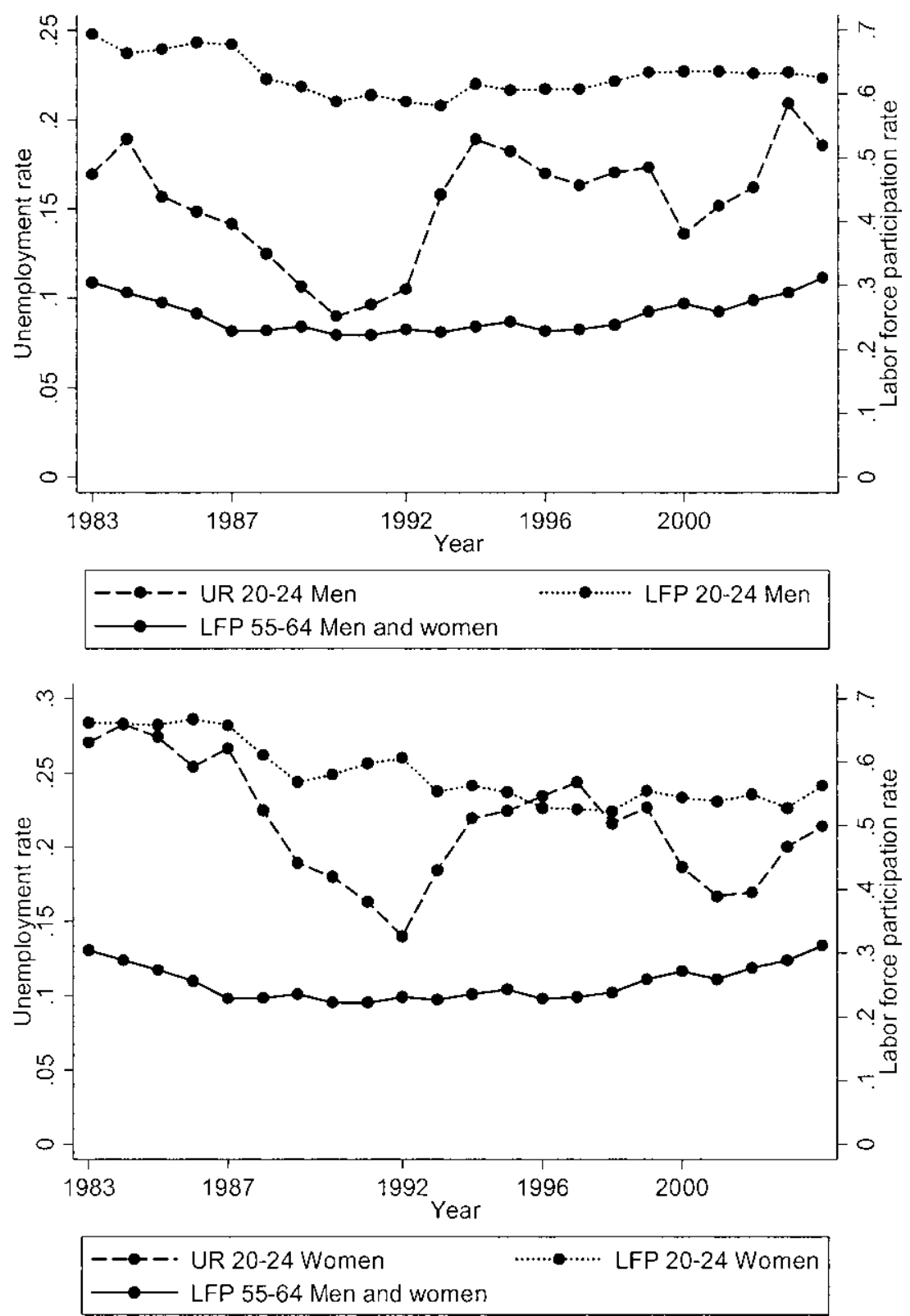

Fig. 1.9 Trends in unemployment and labor force participation of the young compared to the labor force participation of the old by sex Source: European Labor Force Surveys (1983-2004). 

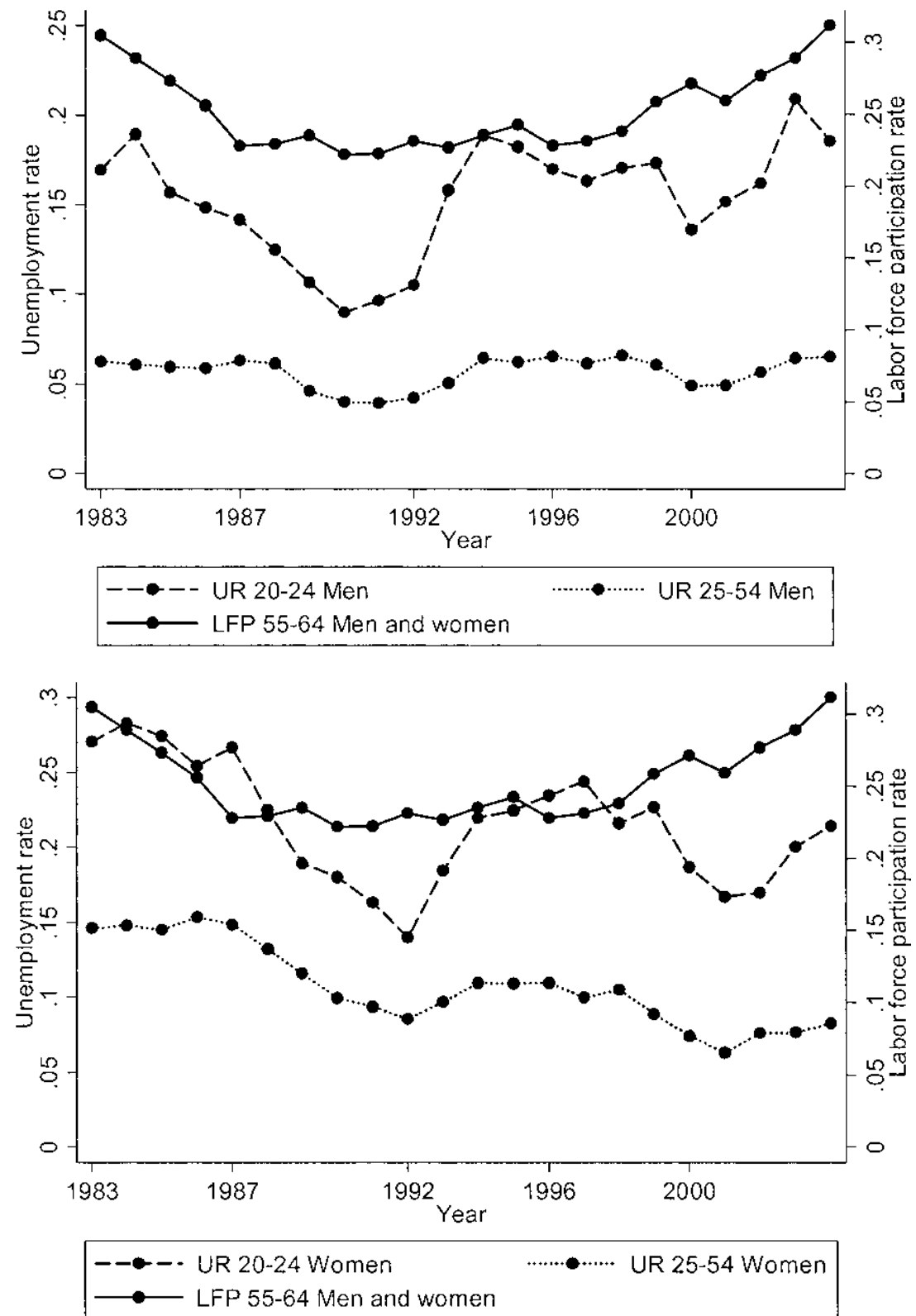

Fig. 1.10 Trends in unemployment of the young and prime aged workers compared to the labor force participation of the old by sex

Source: European Labor Force Surveys (1983-2004). 

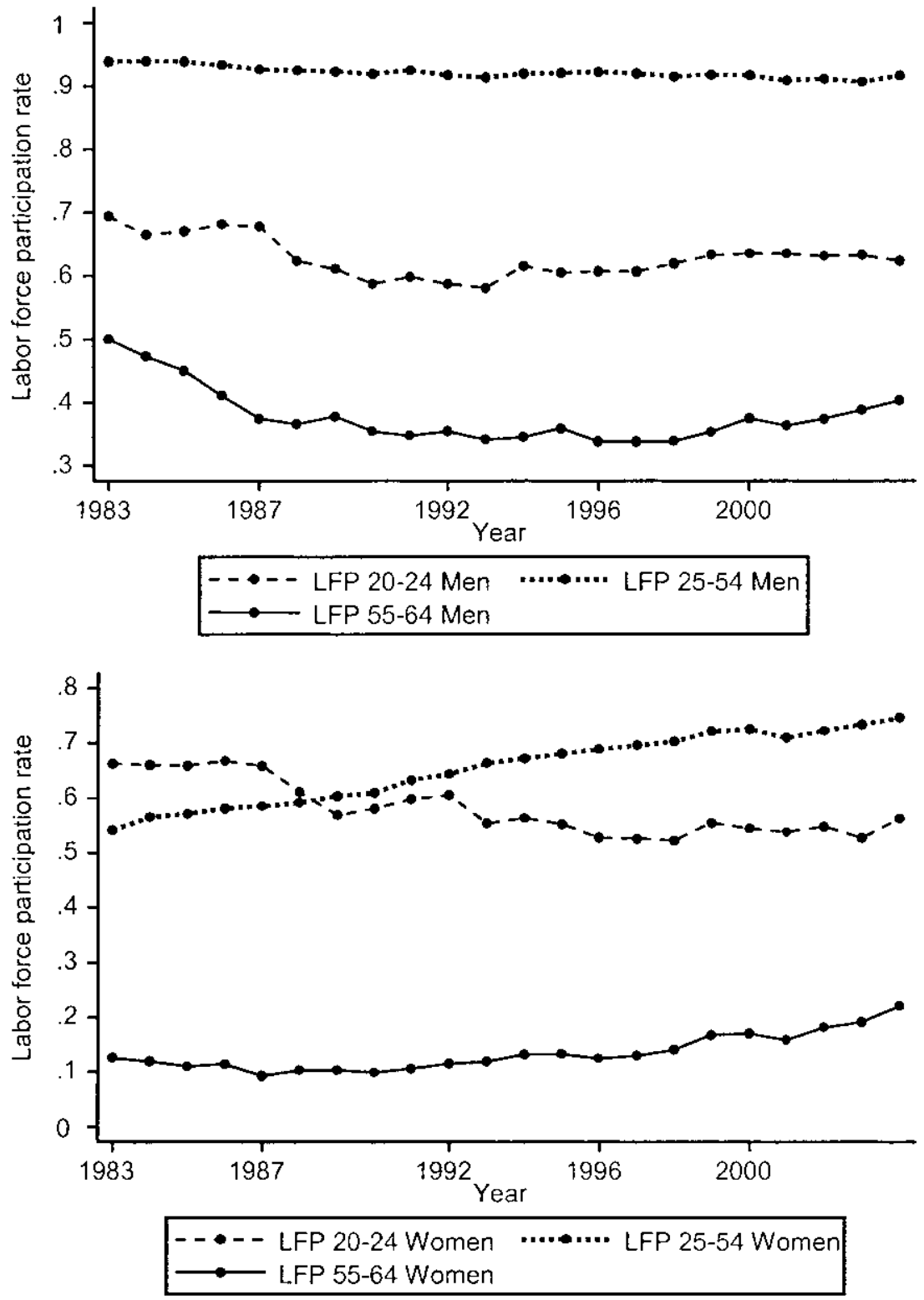

Fig. 1.11 Trends in labor force participation for the three age groups by sex Source: European Labor Force Surveys (1983-2004). 
Table 1.4

Direct effect of elderly labor outcomes on the young (women and men separated)

\begin{tabular}{|c|c|c|c|c|c|c|}
\hline \multirow[b]{2}{*}{ Specification } & \multicolumn{4}{|c|}{ Youth 20-24 } & \multicolumn{2}{|c|}{ Prime age $25-54$} \\
\hline & UR & ER & $\mathrm{SCH}$ & “Ext.”UR & UR & ER \\
\hline \multicolumn{7}{|c|}{ No controls } \\
\hline Levels & $\begin{array}{l}0.536^{* *} \\
(0.252)\end{array}$ & $\begin{array}{c}0.068 \\
(0.272)\end{array}$ & $\begin{array}{l}0.089 \\
(0.205)\end{array}$ & $\begin{array}{c}-0.157 \\
(0.214)\end{array}$ & $\begin{array}{c}0.053 \\
(0.181)\end{array}$ & $\begin{array}{c}0.104 \\
(0.858)\end{array}$ \\
\hline 3-year lag & $\begin{array}{l}0.336 \\
(0.301)\end{array}$ & $\begin{array}{c}0.585^{*} \\
(0.327)\end{array}$ & $\begin{array}{l}-0.627 * * * \\
(0.227)\end{array}$ & $\begin{array}{c}0.042 \\
(0.267)\end{array}$ & $\begin{array}{c}0.341 * \\
(0.197)\end{array}$ & $\begin{array}{c}-0.597 \\
(1.001)\end{array}$ \\
\hline $\begin{array}{l}\text { 5-year } \\
\text { difference }\end{array}$ & $\begin{array}{l}0.589 * * \\
(0.269)\end{array}$ & $\begin{array}{l}0.293 \\
(0.185)\end{array}$ & $\begin{array}{l}-0.090 \\
(0.134)\end{array}$ & $\begin{array}{c}-0.202 \\
(0.125)\end{array}$ & $\begin{array}{c}0.115 \\
(0.109)\end{array}$ & $\begin{array}{c}-0.083 \\
(0.166)\end{array}$ \\
\hline $\begin{array}{l}\text { 5-year log } \\
\text { difference }\end{array}$ & $\begin{array}{l}0.941^{* *} \\
(0.416)\end{array}$ & $\begin{array}{l}0.154 \\
(0.101)\end{array}$ & $\begin{array}{c}-0.074 \\
(0.103)\end{array}$ & $\begin{array}{c}-0.305 \\
(0.192)\end{array}$ & $\begin{array}{c}0.331 \\
(0.348)\end{array}$ & $\begin{array}{c}-0.068 \\
(0.073)\end{array}$ \\
\hline \multicolumn{7}{|c|}{ With controls } \\
\hline Levels & $\begin{array}{l}0.619 * * * \\
(0.164)\end{array}$ & $\begin{array}{l}0.184 \\
(0.131)\end{array}$ & $\begin{array}{l}-0.117 \\
(0.109)\end{array}$ & $\begin{array}{c}-0.067 \\
(0.102)\end{array}$ & $\begin{array}{c}0.150 \\
(0.090)\end{array}$ & $\begin{array}{c}-0.111 \\
(0.247)\end{array}$ \\
\hline 3-year lag & $\begin{array}{l}0.538^{* *} \\
(0.203)\end{array}$ & $\begin{array}{l}0.369^{* *} \\
(0.177)\end{array}$ & $\begin{array}{l}-0.258^{*} \\
(0.148)\end{array}$ & $\begin{array}{c}-0.111 \\
(0.137)\end{array}$ & $\begin{array}{l}0.274^{* *} \\
(0.105)\end{array}$ & $\begin{array}{c}-0.261 \\
(0.278)\end{array}$ \\
\hline $\begin{array}{l}\text { 5-year } \\
\text { difference }\end{array}$ & $\begin{array}{l}0.684 * * * \\
(0.139)\end{array}$ & $\begin{array}{l}0.349 * * \\
(0.159)\end{array}$ & $\begin{array}{l}-0.098 \\
(0.121)\end{array}$ & $\begin{array}{c}-0.252^{*} \\
(0.131)\end{array}$ & $\begin{array}{l}0.198 * * * \\
(0.039)\end{array}$ & $\begin{array}{l}-0.159 * * * \\
(0.057)\end{array}$ \\
\hline $\begin{array}{l}\text { 5-year log } \\
\text { difference }\end{array}$ & $\begin{array}{l}0.020 \\
(0.319)\end{array}$ & $\begin{array}{l}0.430 * * * \\
(0.130)\end{array}$ & $\begin{array}{l}-0.353^{* *} \\
(0.138)\end{array}$ & $\begin{array}{l}-0.622 * * \\
(0.283)\end{array}$ & $\begin{array}{l}-0.416^{* *} \\
(0.158)\end{array}$ & $\begin{array}{l}-0.052 \\
(0.041)\end{array}$ \\
\hline
\end{tabular}

Notes: Reporteds is the coefficient on elderly participation rate. Covariates include GDP per capita, the growth in GDP per capita, and the share of GDP coming from manufacturing sector.

***Significant at the 1 percent level.

**Significant at the 5 percent level.

*Significant at the 10 percent level.

groups have been differently influenced by the global labor force participation of older workers.

As presented in table 1.4, these new regressions do not give different results from those of table 1.2. Whatever the specification, the coefficients are of the same magnitude and display similar significance except for the level regression with controls. This is important since it shows that the results presented in table 1.2 are robust to taking into account differences between sexes. However, these estimates are still confusing for the youth. Table 1.4 displays also the effect of participation of older workers on a different indicator of youth outcome. We have seen in section 1.2 that the youth unemployment is very dependent on the institutional framework and for this reason it may not be a good indicator of the youth labor market performance. When dividing the youth population according to status, differentiating the unemployed, employed, and at school young people is not sufficient. There is still a proportion of individuals that do not belong to any of these categories. Think of the young people who are no longer attending schools but are also not looking for a job because of bad prospects of employment. The "extended" 
Estimating the parameters of I (women and men separated)

\begin{tabular}{|c|c|c|c|c|c|}
\hline & $\gamma$ & $\varphi$ & $\alpha$ & $R^{2}$ & Implied $\bar{I}$ weighting \\
\hline $\begin{array}{l}\text { 1. Iterating over } \gamma \text { and } \varphi \\
\text { with } 0.25 \text { intervals and } \\
\text { regressing LFP of old } \\
\text { on } \bar{I} \text { and covariates }\end{array}$ & \multicolumn{2}{|c|}{ Any values when $\gamma=\varphi$} & 1 & 0.991 & $1 \times \bar{W}+1 \times \overline{W-P V}$ \\
\hline $\begin{array}{l}\text { 2. Iterating over } \varphi \text { with } \\
\gamma=1 \text { with } 0.25 \text { intervals } \\
\text { and regressing LFP of } \\
\text { old on } \bar{I} \text { and covariates }\end{array}$ & 1 & 1 & 1 & 0.991 & $1 \times \bar{W}+1 \times \overline{W-P V}$ \\
\hline $\begin{array}{l}\text { 3. Time series regression } \\
\text { of } L F P \text { of old on } \bar{W} \\
\text { and } \overline{W-P V}\end{array}$ & $-0.458 * * *$ & $-0.464^{* * * *}$ & 1.01 & 0.991 & $1 \times \bar{W}+1.01 \times \overline{W-P V}$ \\
\hline
\end{tabular}

Notes: Reported is the coefficient on the inducements to retire in thousands. Covariates include GDP per capita, the growth in GDP per capita, and the share of GDP coming from manufacturing sector and a sex dummy; $\alpha$ corresponds to the ratio of $\varphi$ over $\gamma$.

***Significant at the 1 percent level.

**Significant at the 5 percent level.

*Significant at the 10 percent level.

unemployment indicator proposed in table 1.4 accounts for this group in addition to conventional unemployment. The coefficients are hardly significant, but they show that the activity of elderly has a negative effect on this indicator. With this result, one observes that the effect of the labor force participation of the old on the young seems to be running contrary to the boxed economy proposition.

As in section 1.5, we turn to models that links the incentives faced by the elderly to the labor market outcomes of the young. The new sample requires that we reestimate the parameter value for $\alpha$ as we did in section 1.4 for women and men together. In this case, we consider specific indicators of incentives for each sex since the inducement to retire has been different for women and men but we estimate the value of $\alpha$ pooling men and women together. Table 1.5 shows that the iteration and the regression procedures give the same result. Overall, $\alpha$ is equal to 1 .

We perform levels regression and five-year difference regression using $\bar{W}$ and one construction of $\bar{I}$. We use $\alpha=1.01$. Results of regressions are presented on table 1.6 and are very similar when we consider either $\bar{W}$ or $\bar{I}$. First, a larger inducement to retire leads to a negative effect on elderly labor force participation, both for levels and difference regressions. Second, levels regressions do not present any significant effect of the incentive to retire on either the unemployment or the employment of the young workers. The difference approach displays, on the contrary, a negative and significant effect on youth unemployment, which is in line with table 1.4 results. However, this should be read with a lot of caution. There does not 


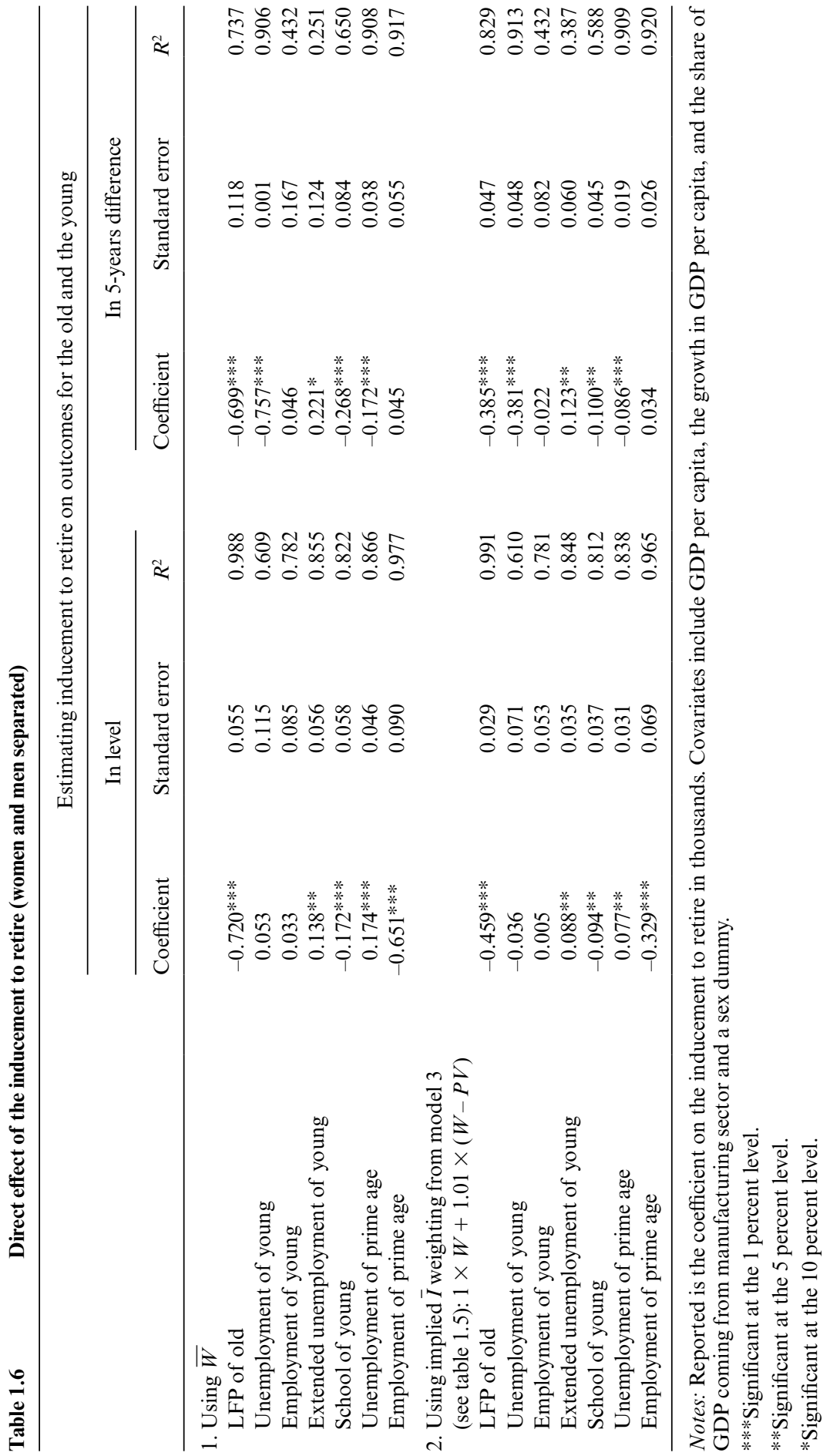


seem to be any effect on the employment rate of the young, which is the key labor market outcome in our view. When we consider the "extended" unemployment indicator, the sign of the coefficient is reversed but still significant.

The results obtained for the prime age group, twenty-five- to fifty-fouryears-old, are contradictory across levels and five-years' differences model specifications, both in table 1.4 and in table 1.5. Overall, we cannot draw any definitive conclusion with respect to the link between early retirement and activity rates among the prime age group.

\subsection{Conclusions}

Belgium is characterized by a relatively high rate of unemployment of the young and a low rate of activity of the elderly workers. The latter is the consequence of high incentives to exit the labor force and these incentives are generally justified in the name of fostering youth employment.

In this chapter we have tested the validity of such a belief. At the outset, we were not expecting too much from these tests for two reasons. First, theoretically one knows that there is no foundation for the idea that there would be such a thing as a fixed lump of labor, implying that less elderly workers means more young workers. Second, the nature of youth unemployment in Belgium is such that it is pretty insensitive to variations in labor demand, but rather is the result of structural weaknesses in the areas of education, unemployment insurance, and wage formation.

In order to proceed with this test, we have constructed average indicators of incentive toward early retirement and we have shown that these incentives explain well variations in activity rates among elderly workers. But when we relate either participation rate of the elderly or the incentive indicators to unemployment or employment of the young, the results are mixed and have to be taken with caution.

First it seems important to know which variable of youth labor market performance is relevant. We have seen that youth unemployment rate is largely influenced by the employment policies toward the young. In this respect it seems preferable to use the employment rate.

Second, we emphasize the sharp contrast between men and women. The results are, however, not different if we consider the aggregate labor market or if we make the distinction between men and women. We have shown that labor outcomes by gender have been slightly different over the period but they do not turn into different results than those obtained with aggregate labor market outcomes.

With these warnings in mind, we do not observe any clear positive link between the fall of labor force participation of elderly and youth employment. The lump of labor conjecture must be rejected for Belgium at least in the private sector to which this chapter is restricted. 


\section{References}

Blondal, S., and S. Scarpetta. 1999. The retirement decision in OECD countries. Organization for Economic Cooperation and Development (OECD) Economics Department Working Paper no. 202. Paris: OECD Economics Department.

Boldrin, M., J. Dolado, J. Jimeno, and F. Perrachi. 1999. The future of pension in Europe. Economic Policy 29:289-320.

European Labour Force Surveys 1983-2004. Luxembourg: Eurostat.

Gruber, J., and D. Wise. 1999. Social Security and retirement around the world. Chicago: University of Chicago Press.

. 2003. Social Security and retirement around the world: Micro-estimation. Chicago: University of Chicago Press.

High Employment Council. 2007. Rapport Annuel, Bruxelles. Available at: www .emploi.belgique.be.

Jousten, A., M. Lefèbvre, S. Perelman, and P. Pestieau. 2005. Social Security in Belgium: Distributive outcomes. Institute for the Study of Labor(IZA) Discussion Paper no. 1486.

Layard, R., S. Nickell, and R. Jackman. 1991. Unemployment: Macroeconomic performance and the labour market. Oxford: Oxford University Press.

Organization for Economic Cooperation and Development (OECD). 2006a. OECD Labour Force Indicators Database. Paris: OECD.

. 2006b. OECD National Accounts Database. Paris: OECD.

Office national de l'Emploi (ONEM). 2001. Les bénéficiares d'allocations d'attente et de transition. Direction Etudes et direction Statistiques et Publications. Bruxelles: ONEM. 